Supporting Information

\title{
Dual-Functional Aligned and Interconnected Graphite Nanoplatelet Networks for Accelerating Solar Thermal Energy Harvesting and Storage within Phase Change Materials
}

$\mathrm{Si} \mathrm{Wu}^{\dagger, \S}$, Tingxian $\mathrm{Li}^{*}{ }^{\dagger}, \S$, Minqiang $\mathrm{Wu}^{\dagger}$, Jiaxing $\mathrm{Xu}^{\dagger}$, Jingwei Chao ${ }^{\dagger}$, Yihao $\mathrm{Hu}{ }^{\dagger}$, Taisen Yan ${ }^{\dagger}$, Qin-Yi Li $\ddagger$ Ruzhu Wang ${ }^{\dagger} * *$

$\dagger$ Research Center of Solar Power \& Refrigeration, School of Mechanical Engineering Shanghai Jiao Tong University, Shanghai 200240, P. R. China

$\$$ Department of Aeronautics and Astronautics, Kyushu University, Fukuoka 819-0395, Japan

$\S$ These authors contributed equally to this work.

*Email: Litx@sjtu.edu.cn.

*Email: Rzwang@sjtu.edu.cn. 
Note S1: The relationship between mass and volume fractions of WEG in the

\section{$\underline{\text { composite block }}$}

Due to the mechanical compression at high pressure, the composite blocks are compact and thus the pores existing in the composite block can be ignorable. Then the relationship between the volume fraction $(\phi)$ and mass fraction $(\varphi)$ of graphite nanosheet can be obtained:

$$
\phi=\frac{\frac{\varphi}{\rho_{\mathrm{G}}}}{\frac{\varphi}{\rho_{\mathrm{G}}}+\frac{1-\varphi}{\rho_{\mathrm{PCM}}}}
$$

where $\rho_{\mathrm{PCM}}$ and $\rho_{\mathrm{G}}$ are the density of PCM and graphite nanosheet, respectively. Their values are $2.0 \sim 2.2 \mathrm{~kg} \mathrm{~m}^{-3}$ and $1.2 \sim 1.4 \mathrm{~kg} \mathrm{~m}^{-3}$. The relationship between mass and volume fractions of WEG in the composite block is listed in Table S1.

The thermal conductivities of our composites as a volume fraction of WEG is shown in Figure S6.

\section{Note S2: The determination of the photothermal etching depth}

The etching depth can be roughly determined by calculating the mass loss of the composite block during the photothermal etching. The mass residue $(\varepsilon)$ can be obtained by weighing the composite block with a high-accuracy balance for every five minutes (Figure S13b). Then, the etching depth change $(\Delta h)$ can be calculated by proportionable mass change of TME:

$$
\begin{gathered}
\varepsilon=\frac{m-\Delta m}{m} \\
\frac{\Delta h}{h}=\frac{\Delta m}{m_{\mathrm{TME}}} \\
m_{\mathrm{TME}}=(1-\varphi) m
\end{gathered}
$$


where $m$ is the total mass of the composite block, $m_{\text {TME }}$ is the total mass of TME in the composite block, $h$ is the total depth of the composite block along the direction of light irradiation and $\varphi$ is the mass fraction of graphite in the composite block.

\section{Note S3: The preparation of carbon black coating}

The carbon black (CB) particles with diameters in the range of 30-45 $\mathrm{nm}$ and specific surface area in the range of $120-130 \mathrm{~m}^{2} \mathrm{~g}^{-1}$ were coated on the original 2D surface and etched 3D structure surface of the PCC blocks by spray method. Firstly, the $\mathrm{CB}$ particles were added into ethanol to prepare the uniform suspension with $\mathrm{CB}$ concentration of $\sim 10 \mathrm{mg} \mathrm{mL}^{-1}$ with the help of ultrasonic mixing. Then, the homogeneous suspension was poured into the coating machine and sprayed on the surface of the as-prepared PCC block. Lastly, the wet coating was dried under room temperature and vacuum condition. The thickness of $\mathrm{CB}$ coating on the $2 \mathrm{D}$ surface was controlled at about $10 \mu \mathrm{m}$ and the quantity of $\mathrm{CB}$ coating on two kinds of surfaces were kept the same. The morphology of $\mathrm{CB}$ coating is demonstrated in Figure S14. 

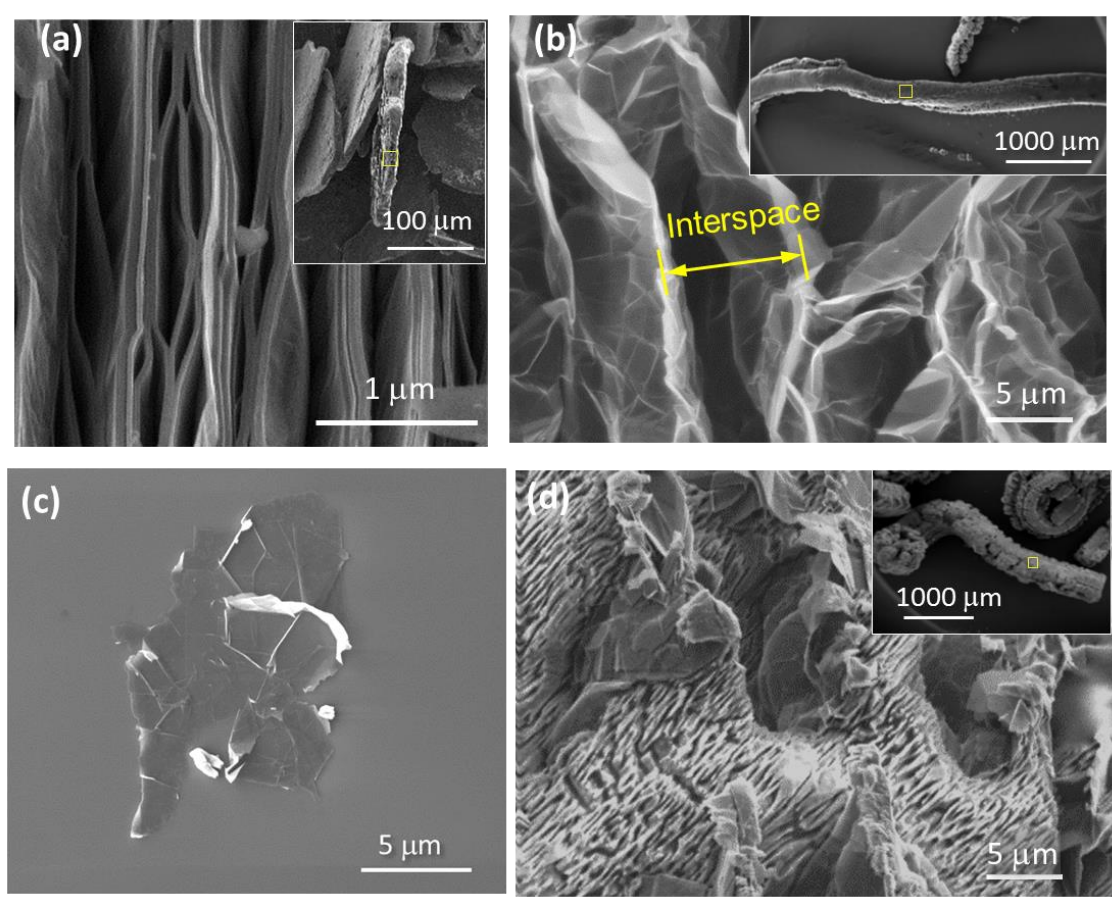

Figure S1. (a) The cross-plane microstructure of the graphite intercalated compound (GIC). The inset shows the intact GIC. (b) Microstructure of the worm-like expanded graphite (WEG). The inset shows the long-chain structure of a piece of WEG in diameter about $500 \mu \mathrm{m}$ and length more than $3000 \mu \mathrm{m}$. (c) The constitutive GNP (graphite nanoplatelet) on the WEG. It is obtained from alcoholic solution of WEG by drastic ultrasonic treatment (Power: 500W; Time: $30 \mathrm{~min}$ ) and still composed of many smaller-sized GNP at lateral size less than $5 \mu \mathrm{m}$. (d) Microstructure of the TME-coated WEG. The inset indicates an intact TME-coated WEG. 
a

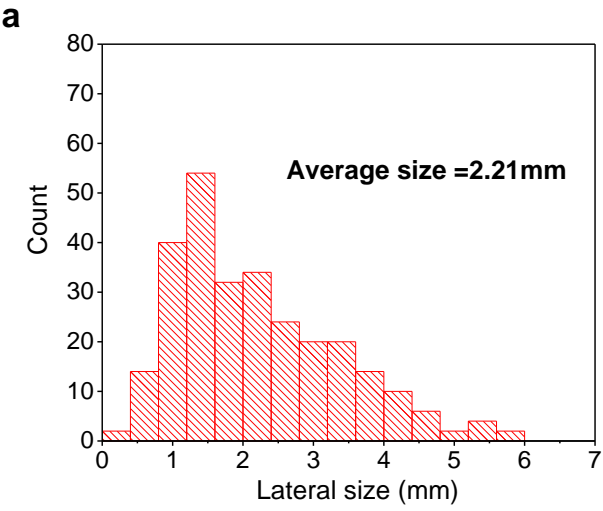

b

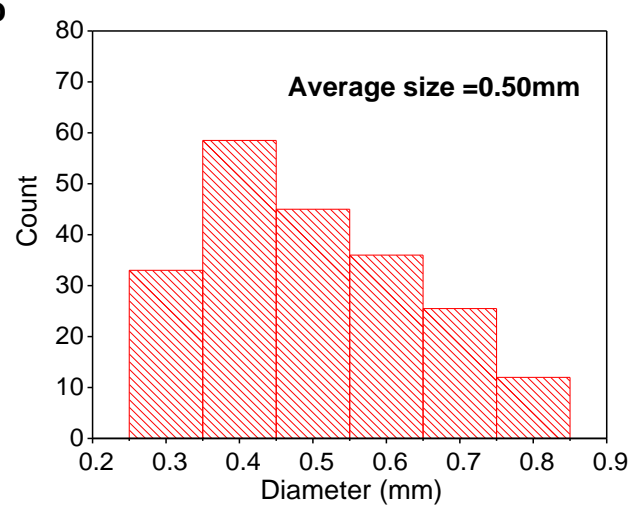

Figure S2. (a) Lateral size and (b) diameter distribution statistics of the WEG. The WEG has different intrinsic states like curve and straight. The sizes are measured in its intrinsic state and the maximum length is considered as the effective length. 

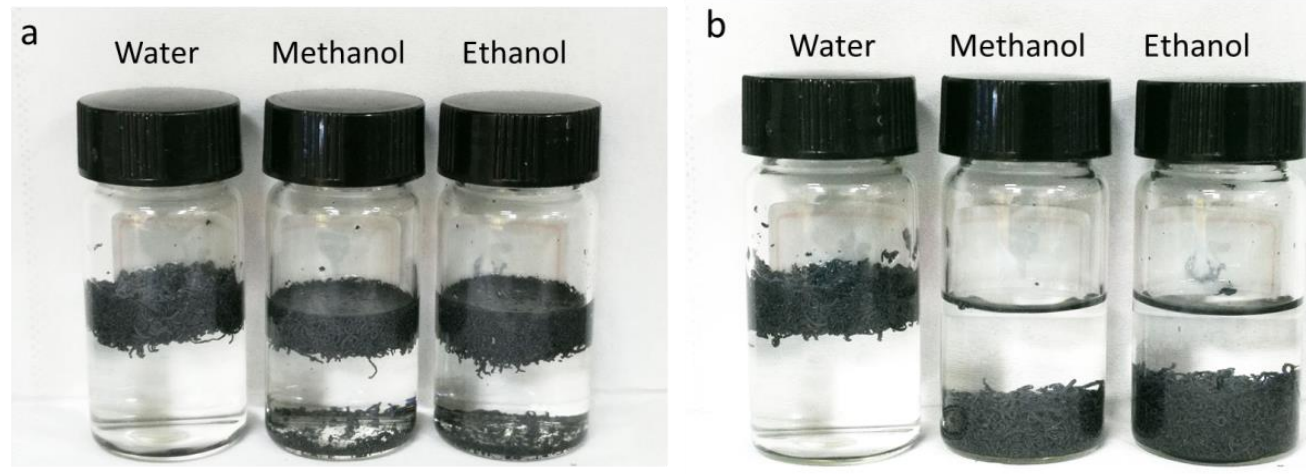

Figure S3. Comparison of dispersion of the WEG in water, methanol and ethanol.

(a) Initial state. (b) After one hour. 


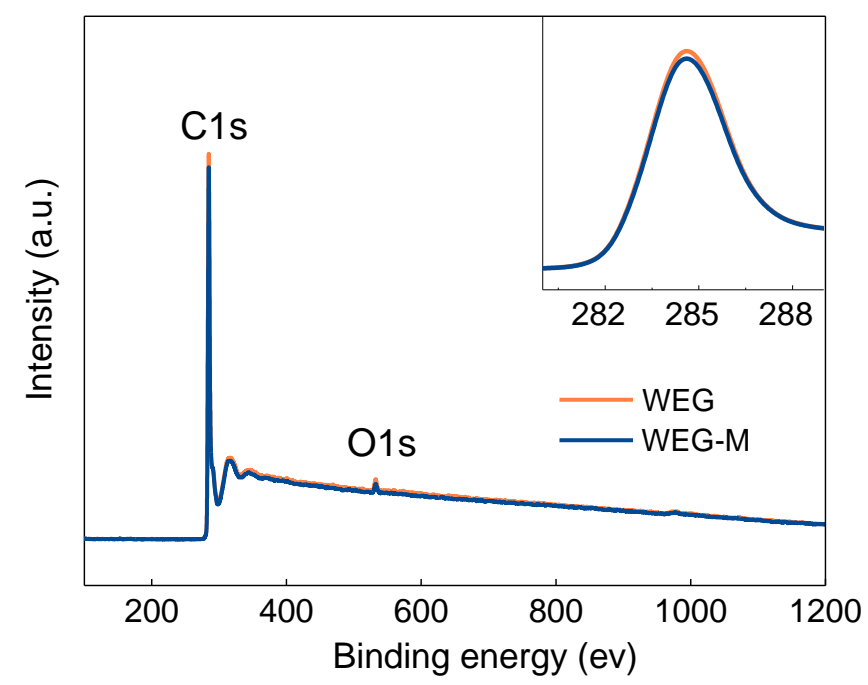

Figure S4. XPS spectrums of WEG and methanol-treated WEG (WEG-M). The inset is the $\mathrm{C}$ 1s XPS spectrum showing graphitic $\mathrm{C}=\mathrm{C}(284.8 \mathrm{eV})$. 

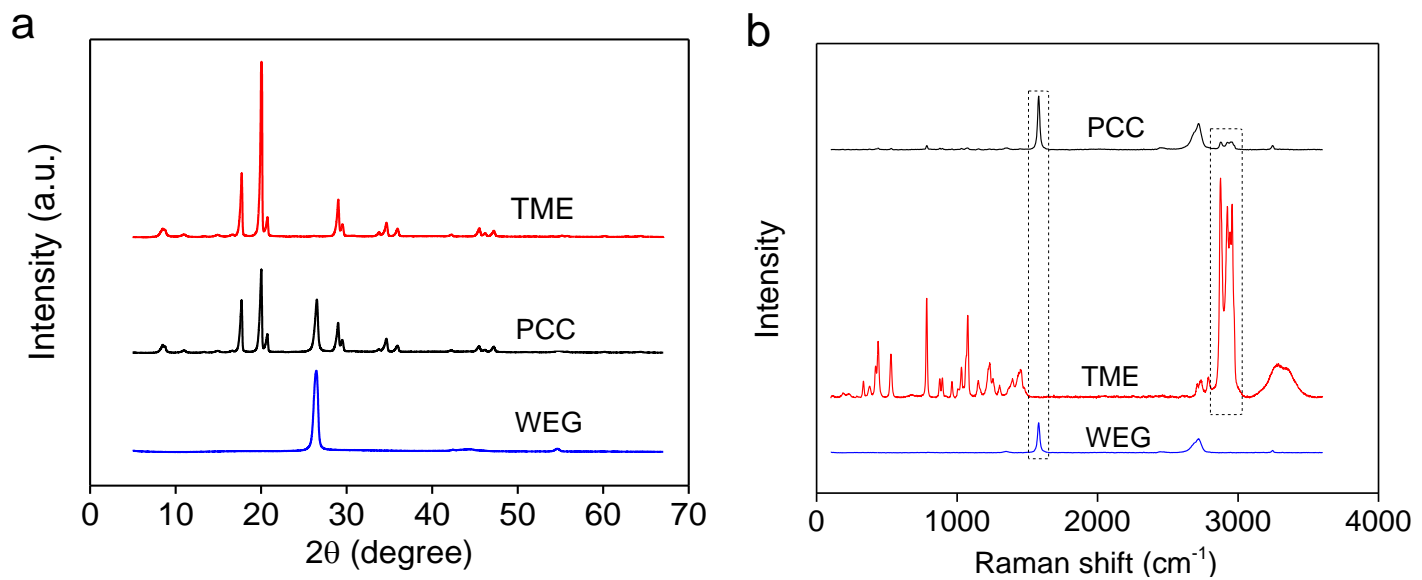

Figure S5. (a) XRD results and (b) Raman spectrums of WEG, TME and PCC. 


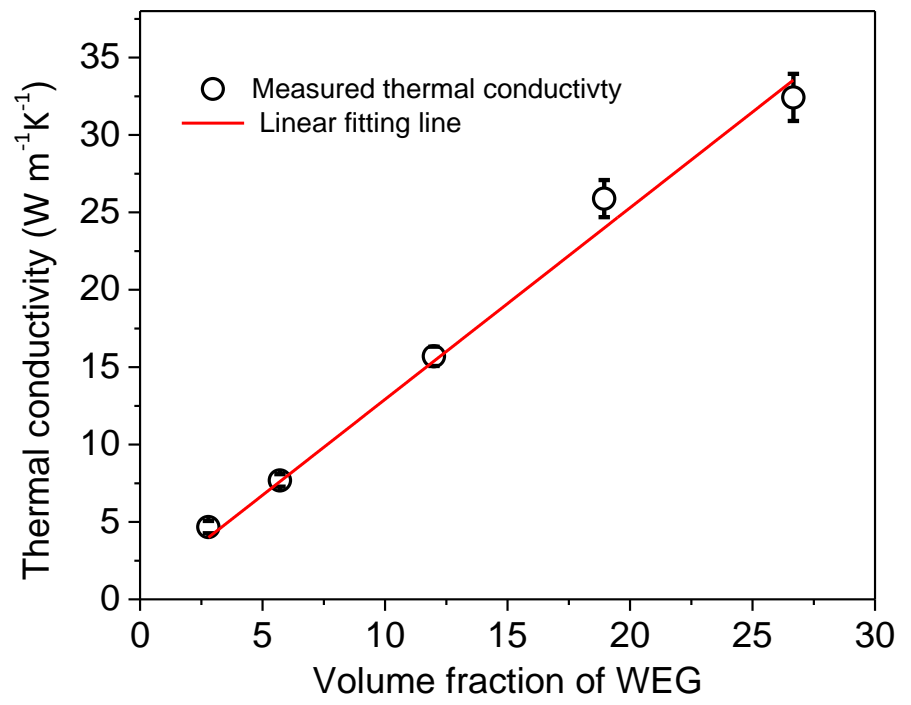

Figure S6. The thermal conductivity of PCCs as a function of volume fraction of the WEG. 


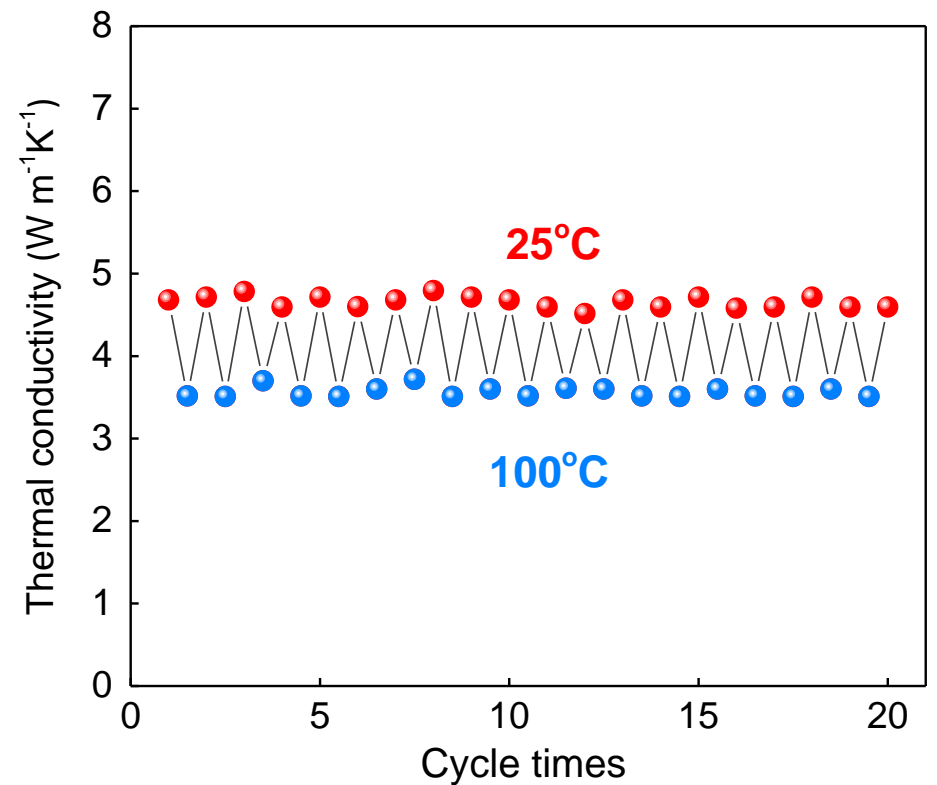

Figure S7. Cyclic stability of the in-plane thermal conductivity of PCC-5 block. 


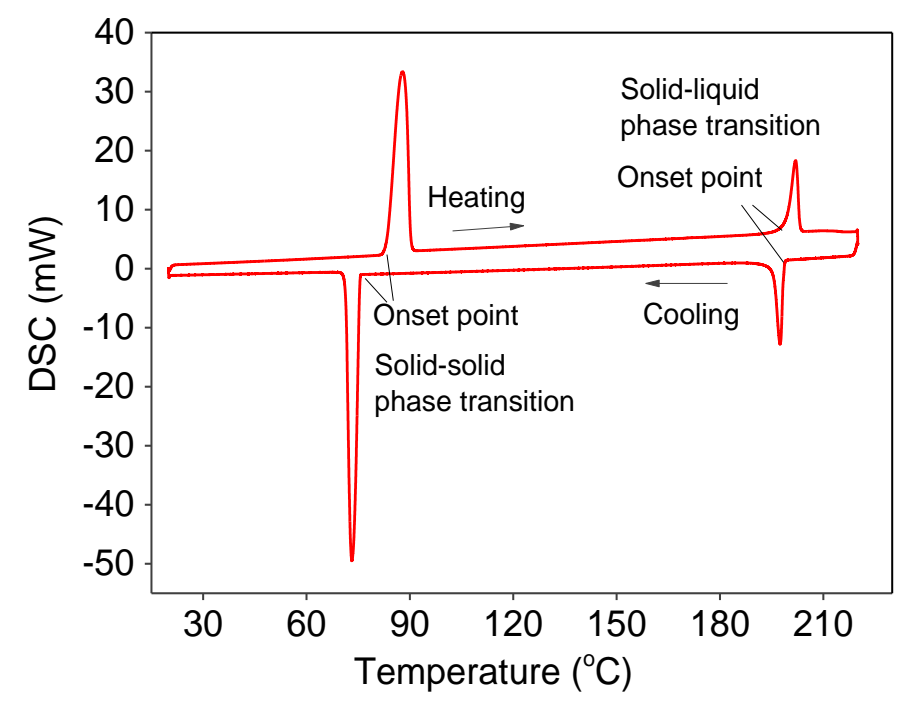

Figure S8. DSC curve of the pristine TME in the range of temperature from 25

${ }^{\circ} \mathbf{C}$ to $220{ }^{\circ} \mathbf{C}$. The measurement is performed at a pressure-tight vessel and the heating/cooling rates are both at $10{ }^{\circ} \mathrm{C} \min ^{-1}$. In the heating process, the solid-solid phase transition takes place at $83.8^{\circ} \mathrm{C}$, and solid-liquid phase transition starts at about $201{ }^{\circ} \mathrm{C}$ 

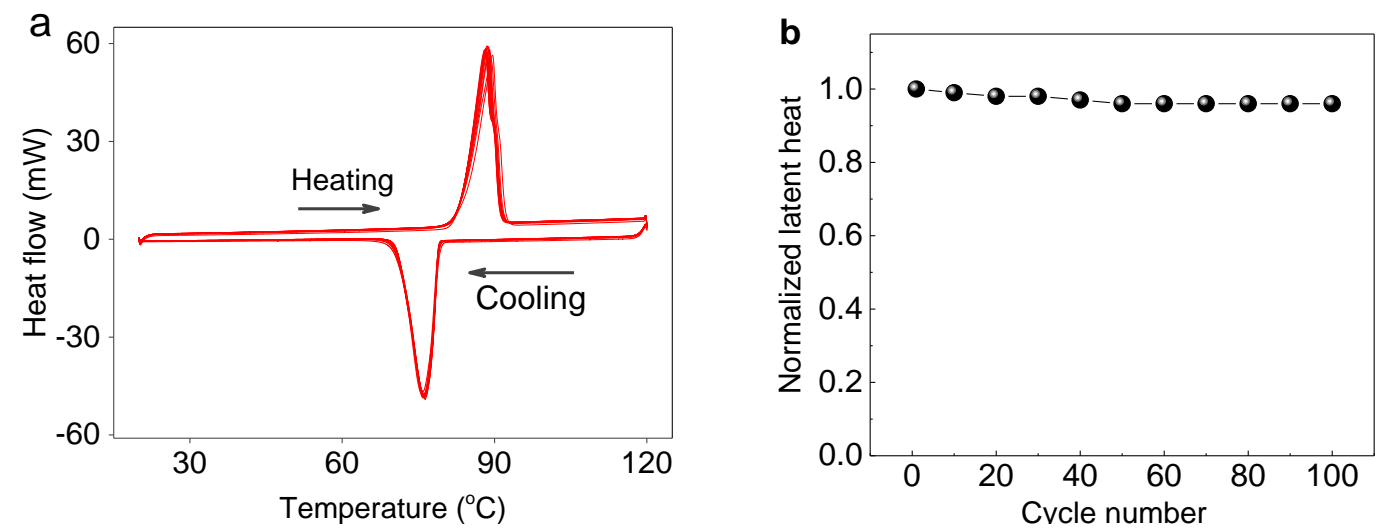

Figure S9. (a) DSC curves of PCC-5 block during continuous 100 heating/cooling cycles. (b) Normalized latent heat as a function of cycle number. 


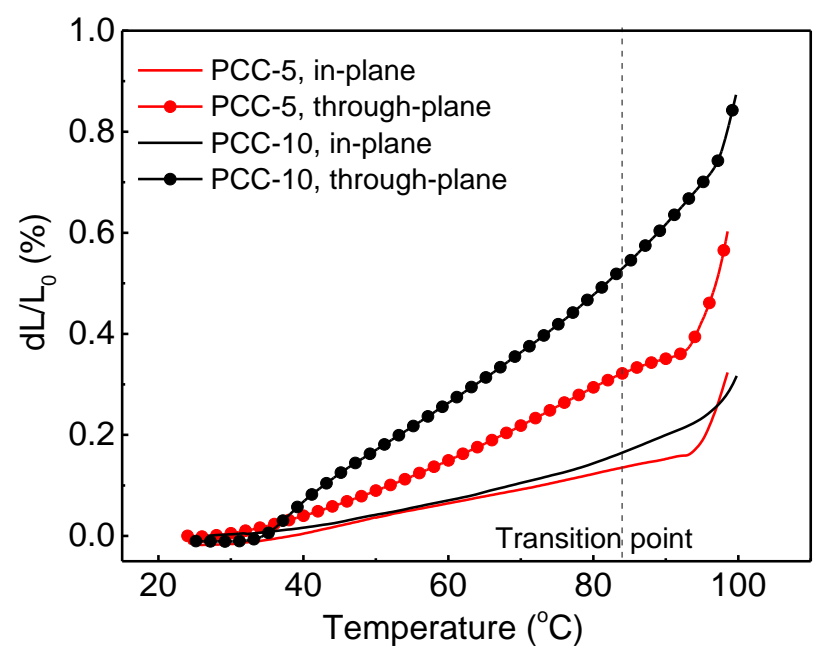

Figure S10. The in-plane and through-plane thermal expansions of PCC-5 and PCC-10 blocks. 


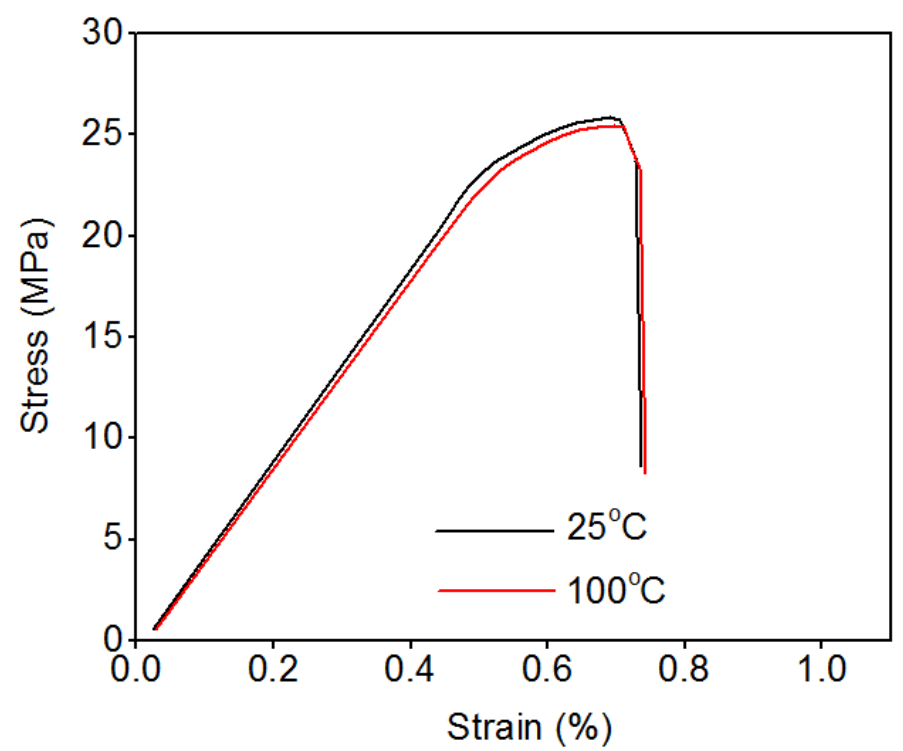

Figure S11. Compression stress-strain curves of PCC-10 block at $25^{\circ} \mathrm{C}$ and $100^{\circ} \mathrm{C}$ 

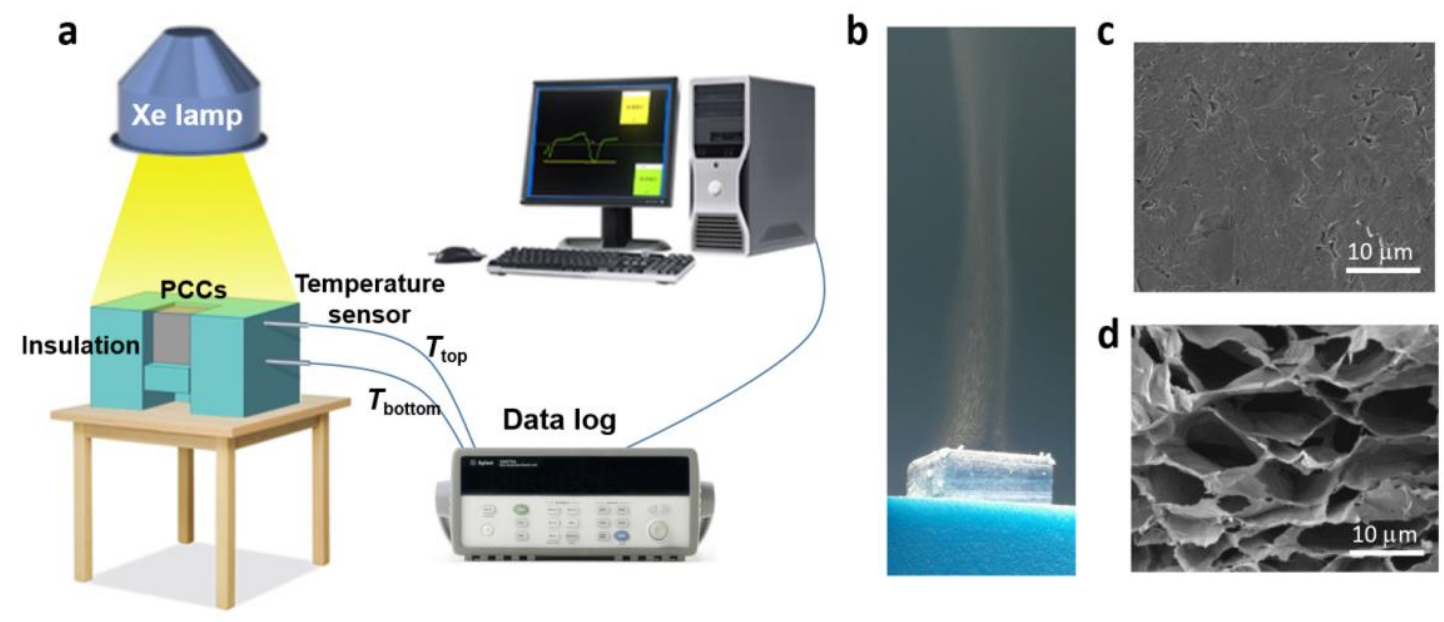

Figure S12. Experimental setup and thermal etching treatment. (a) Schematic of experimental setup. (b) The digital photo of the PCC block showing the evaporating TME. The simulated light intensity is at $5 \mathrm{~kW} \mathrm{~m}^{-2}$. (c) The microstructure image of the surface of PCC block before the etching treatment. (d) The microstructure image of the surface of PCC block after the etching treatment. The optical cavities and naked GNPs are clearly demonstrated. 

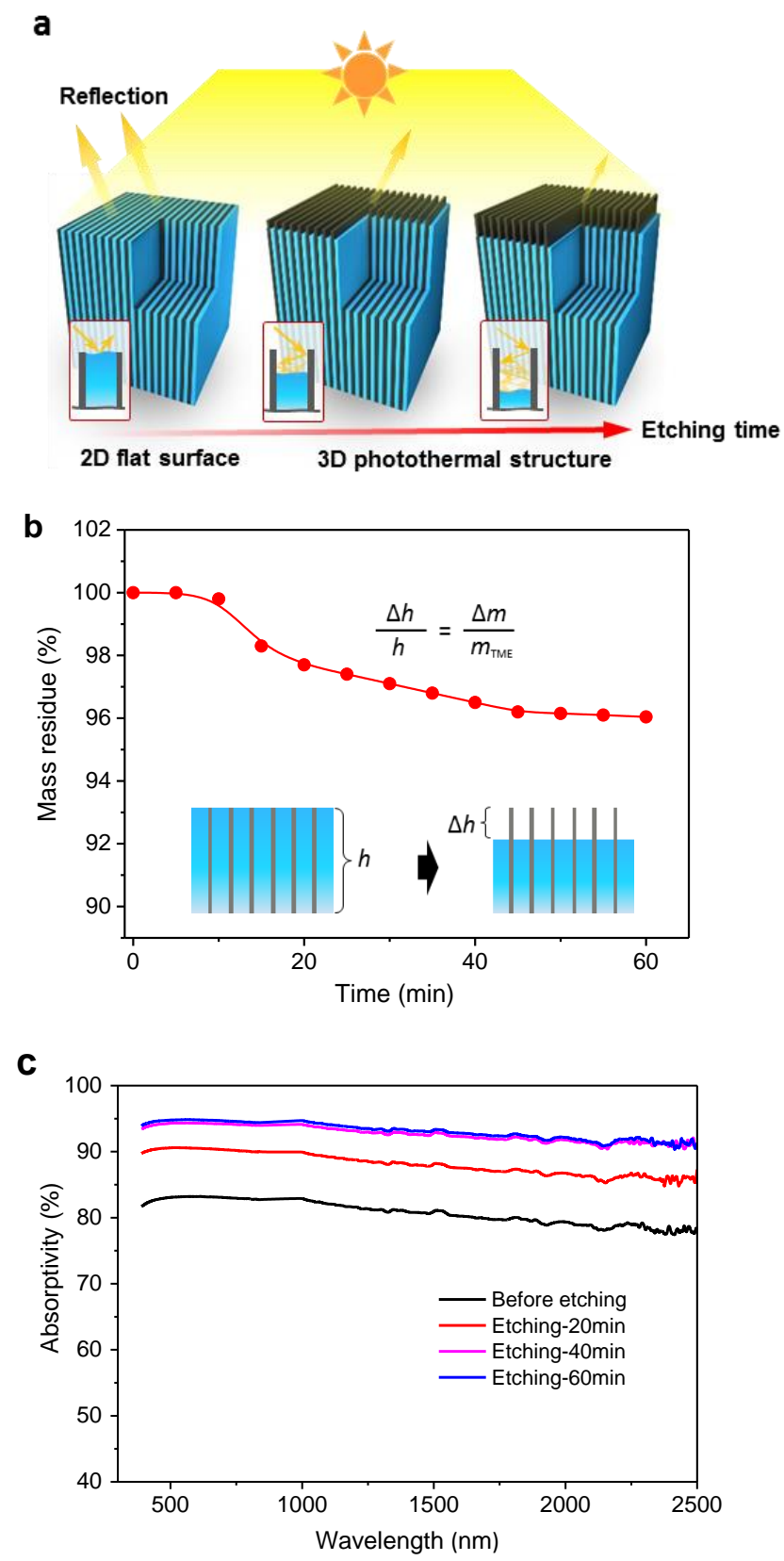

Figure S13. (a) Evolution of the surface structure of PCC block and suppressed light reflectivity by 3D photothermal structure. (b) Variation of mass residue of composite block with time during photothermal etching under a concentrated light with intensity of $5 \mathrm{~kW} \mathrm{~m}{ }^{-2} . \Delta h$ represents the etching depth, $m \mathrm{TME}$ and $\Delta m$ represent the total mass and evaporated mass of TME, respectively. (c) UV-vis-NIR spectra of surface absorptivity of the PCC-5 block before and after etching treatment for $20 \mathrm{~min}, 40 \mathrm{~min}$ and $60 \mathrm{~min}$. 

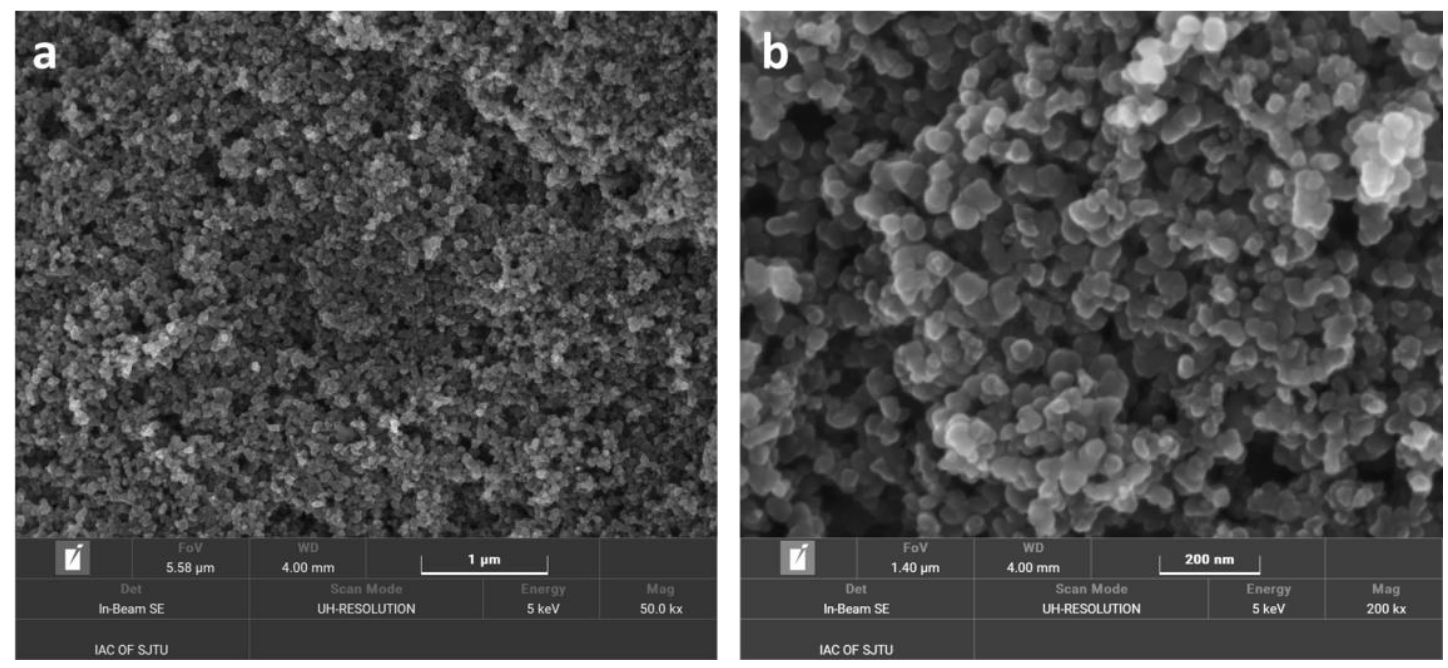

Figure S14. Surface morphology of 2D surface with carbon black coating (CB@2D surface) in different magnification times of (a) x50,000 and (b) x200,000. 

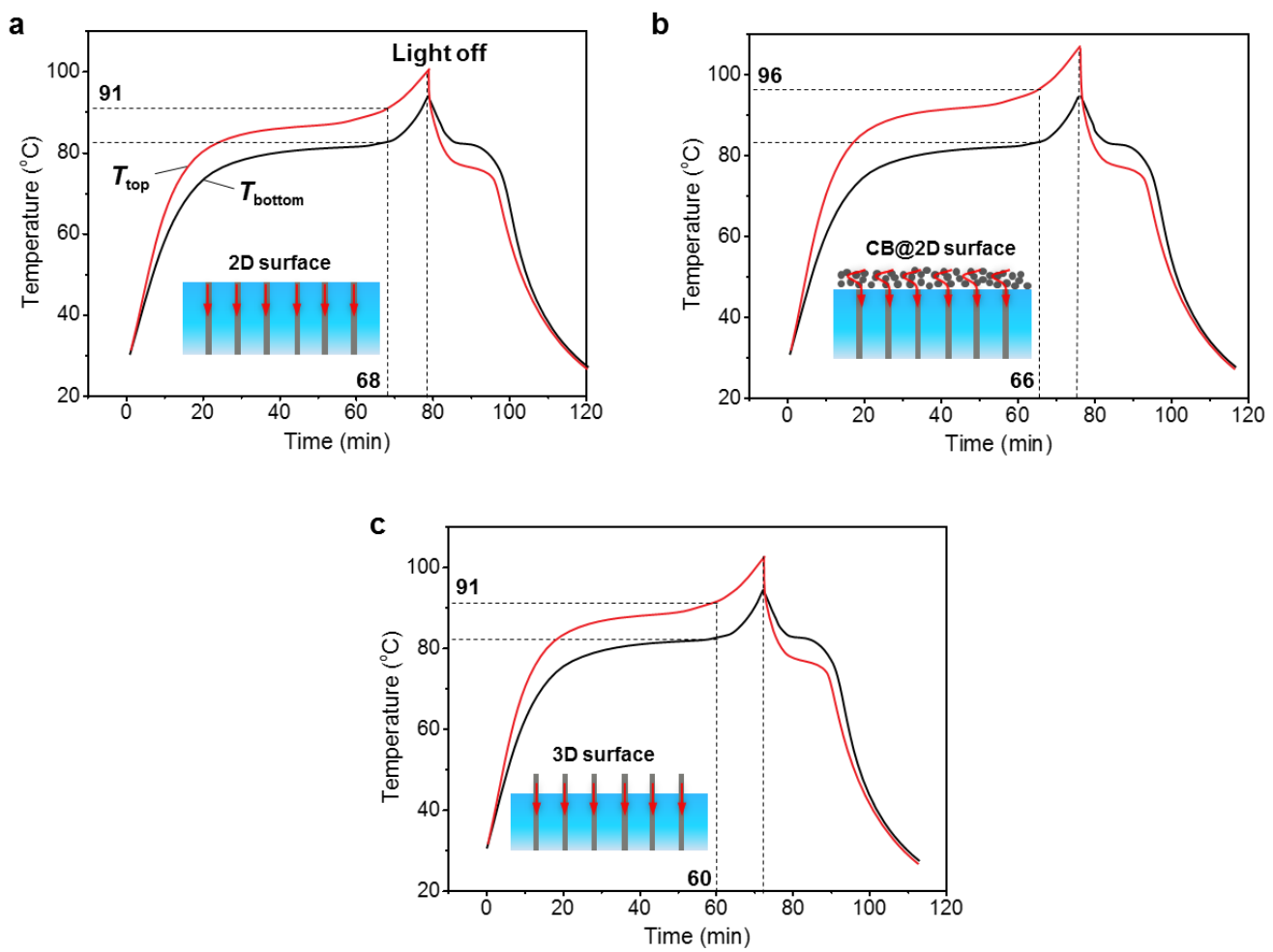

Figure S15. Temperature profiles of top and bottom surfaces of the PCC-5 block with three kinds of photothermal surfaces illuminated at intensities of $1.5 \mathrm{~kW}$ $\mathbf{m}^{-2}$. (a) 2D surface. (b) CB@2D surface. (c) 3D surface. The red and black lines represent the top and bottom surface temperatures of the sample, respectively. 


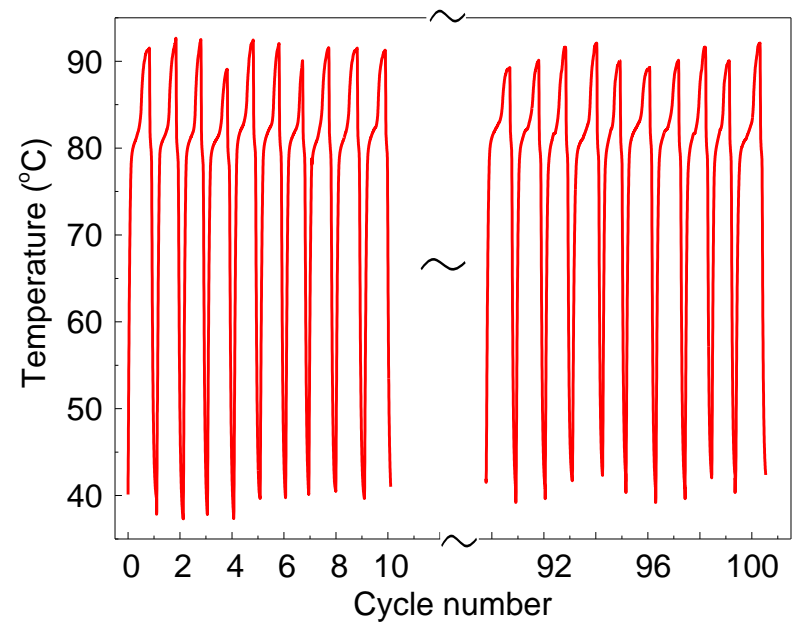

Figure S16. Cyclic stability test of the PCC block for 100 charging/discharging cycles. 
Table S1 The relationship between mass fraction and volume fraction of WEG inside PCCs.

\begin{tabular}{ll} 
Mass fraction of WEG (wt.\%) & Volume fraction of WEG (vol.\%) \\
\hline 5 & 2.8 \\
10 & 5.7 \\
20 & 12.0 \\
30 & 18.9 \\
40 & 26.7
\end{tabular}


Table S2 The comparisons of thermal conductivity enhancement and latent heat $(\Delta H)$ of phase change composites from literatures and our work.

\begin{tabular}{|c|c|c|c|c|c|c|}
\hline PCMs & $\lambda \mathrm{PCM}$ & $\lambda$ com & $\begin{array}{l}\varphi_{\text {graphite }} \\
(\%)\end{array}$ & $\Delta H$ & $\eta$ & Refs. \\
\hline \multicolumn{7}{|l|}{ Graphite foam-based } \\
\hline PEG (polyethylene glycol) & 0.2 & 3.5 & 18 & 76.1 & 0.97 & {$[34]$} \\
\hline Erythritol & 0.72 & 3.77 & 25 & 251 & 0.21 & {$[43]$} \\
\hline PW (Paraffin wax) & 0.2 & 2.6 & 22 & 160 & 0.59 & {$[44]$} \\
\hline PEG (polyethylene glycol) & 0.2 & 10.86 & 27 & 60.3 & 2.01 & {$[45]$} \\
\hline \multicolumn{7}{|l|}{ Graphene aerogel-based } \\
\hline PW (Paraffin wax) & 0.2 & 0.274 & 3 & 213 & 0.46 & {$[18]$} \\
\hline PEG (polyethylene glycol) & 0.2 & 1.35 & 5.3 & 156.1 & 1.27 & {$[31]$} \\
\hline PW (Paraffin wax) & 0.2 & 2.99 & 6 & 190.2 & 2.49 & {$[19]$} \\
\hline SA (Stearic acid) & 0.2 & 3.21 & 10 & 152 & 1.61 & {$[24]$} \\
\hline TD (Tetradecanol) & 0.2 & 1.09 & 10 & 181.4 & 0.55 & {$[47]$} \\
\hline \multicolumn{7}{|l|}{ Expanded graphite-based } \\
\hline PA/PAN (Palmitic Acid/polyaniline) & 0.2 & 1.08 & 7.86 & 157.7 & 0.69 & {$[49]$} \\
\hline PW (Paraffin wax) & 0.2 & 4.75 & 20 & 158.5 & 1.19 & {$[51]$} \\
\hline ODE/PS (Neoctadecane/polystyrene) & 0.6 & 19.0 & 36 & 81.82 & 0.88 & {$[52]$} \\
\hline PG (Pentaglycerine) & 0.23 & 0.944 & 4 & 160.1 & 1.03 & {$[53]$} \\
\hline SA (Stearic acid) & 0.2 & 3.56 & 10 & 163.5 & 1.78 & {$[54]$} \\
\hline TME (Trimethylolethane) & 0.2 & 4.64 & 5 & 164.6 & 4.64 & $\begin{array}{l}\text { This } \\
\text { work }\end{array}$ \\
\hline
\end{tabular}

Note: The literature numbers are corresponding to those in the main text. 
Table S3 The solid-solid phase transition temperatures and latent heats of the pristine TME and PCCs.

\begin{tabular}{llllll}
\hline $\begin{array}{l}\text { WEG } \\
\text { loading } \\
(\mathrm{wt} \%)\end{array}$ & $\begin{array}{l}\text { Phase transition } \\
\left({ }^{\circ} \mathrm{C}\right)(\text { Endo })\end{array}$ & $\begin{array}{l}\text { Phase transition } \\
\left({ }^{\circ} \mathrm{C}\right)(\text { Exo })\end{array}$ & $\begin{array}{l}\text { Latent heat } \\
\left(\mathrm{J} \mathrm{g} \mathrm{g}^{-1}\right)(\text { Endo })\end{array}$ & $\begin{array}{l}\text { Latent heat } \\
\left(\mathrm{J} \mathrm{g}^{-1}\right)(\text { Exo })\end{array}$ & $\begin{array}{l}\text { Calculated Latent } \\
\text { heat }\left(\mathrm{J} \mathrm{g}^{-1}\right)(\text { Endo })\end{array}$ \\
\hline 0 & 83.8 & 71.7 & 172.9 & 157.1 & 172.9 \\
5 & 84.9 & 77.7 & 164.6 & 152.6 & 164.2 \\
10 & 83.8 & 77.7 & 152.8 & 145.2 & 155.6 \\
20 & 83.6 & 77.4 & 134.1 & 127.1 & 138.3 \\
30 & 83.8 & 77.6 & 113.1 & 107.2 & 121 \\
40 & 82.3 & 77.1 & 108.2 & 103.7 & 103 \\
\hline
\end{tabular}

